\title{
PERFORMANCE OF STEEL-REINFORCED SQUARE CONCRETE-FILLED STEEL HOLLOW SECTION (SRSCFSHS) COLUMNS UNDER UNIAXIAL COMPRESSION
}

\author{
Jing-ming Cai ${ }^{1}$, Jin-long $\mathrm{Pan}^{1,{ }^{*}}$ and Yu-fei $\mathrm{Wu}^{2}$ \\ ${ }^{1}$ Key laboratory of concrete and pre-stressed concrete structures of Ministry of Education, \\ Southeast University, Nanjing, China \\ ${ }^{2}$ Department of Civil and Architectural Engineering, City University of Hong Kong, Hong Kong, China \\ *(Corresponding author: E-mail: jinlongp@gmail.com)
}

Received: 18 February 2015; Revised: 10 December 2015; Accepted: 5 January 2016

\begin{abstract}
Due to high load carrying capacity and convenience of designing column-beam connections, steel-reinforced square concrete-filled steel hollow section (SRSCFSHS) columns have been increasingly employed in the structural engineering. In this study, the mechanical behaviors of SRSCFSHS columns were numerically investigated with the software of ABAQUS/standard solver. To verify the validity of the finite element models of the composite columns, the simulation results were compared with the existing experimental results, and good agreement was achieved. According to the simulation results of SRSCFSHS columns, the encased section steel could restrain the generation or propagation of cracks in core concrete thus the composite column can obtain a higher strength and better ductility than that of normal square concrete filled steel tube (CFST) columns. Then, a total of twenty-six SRSCFSHS columns were numerically studied to examine the effect of steel tube ratio $\left(\alpha_{t}\right)$, section steel ratio $\left(\alpha_{s}\right)$, concrete strength $\left(f_{\mathrm{cu}}\right)$, yield strength of steel tube $\left(f_{\mathrm{y}}^{\mathrm{t}}\right)$, yield strength of section steel $\left(f_{\mathrm{y}}^{\mathrm{s}}\right)$ and the slenderness ratio $(\lambda)$ on the mechanical properties of the SRSCFSHS columns under uniaxial compression. A new model was then proposed since the model in Eurocode 4 comparatively underestimated the strength of SRSCFSHS column. Based on the comparison between the calculation results from the proposed approach and experimental results, the proposed model can provide reliable prediction of the strength of SRSCFSHS columns.
\end{abstract}

Keywords: SRSCFSHS columns, finite element analysis, mechanical behavior, parametric study, new approach

DOI:10.18057/IJASC.2016.12.4.3

\section{INTRODUCTION}

Over the last several decades, the steel-concrete composite systems have been widely used in in the construction of modern buildings and bridges, especially in regions with high seismic precautionary intensity [1-3]. For design of column members of these modern structures, the typical composite systems such as concrete filled steel tubes (CFSTs) and steel reinforced concrete (SRC) are commonly used.

It is well known that CFST structures can offer numerous structural benefits, including high strength, favorable fire resistance and ductility, large energy absorption capacities and so on [4-7]. There are many cross section types for CFST columns, among which square and circle CFST columns are the most typical ones. It is noted that the local buckling is more likely to occur in CFST columns with square cross-sections hence the square CFST columns have a relative low load carrying capacity and ductility [8]. However, the square CFST column is still increasingly used in construction of structures for the reasons of being easier in beam-to-column connection design, high cross sectional bending stiffness and good aesthetic effects. Moreover, with increasing span of bridges and height of buildings, the cross section area of a square CFST column is often designed large enough to provide required high load carrying capacity. For example, the side length of square CFST columns in the first story of Shenzhen KingKey Financial Center even reach $4000 \mathrm{~mm}$ [9]. Such a large cross section of a column may result in reduced useful indoor space and high risk of material defect. Thus, it is important to improve both the carrying capacity and ductility of square CFST column. 
As another kind of composite structures, the steel reinforced concrete (SRC) structures, which are composed of concrete, section steel, longitudinal steel bars and transverse steel bars, are also widely used due to their advantages in terms of high sectional strength [10-12] However, the SRC columns need formwork for casting concrete and transverse reinforcement is also needed to prevent the concrete from spalling and buckling of longitudinal steel reinforcement under axial load and fire hazard. Moreover, the construction process of SRC structures is relative complicated, and the outer concrete around section steel is easily crushed under horizontal cyclic loading [13]

Nowadays, a new form of composite column, namely steel-reinforced square concrete-filled steel hollow section (SRSCFSHS) columns, has been proposed. As shown in Figure 1, a SRSCFSHS column normally consists of section steel reinforced concrete inside and a square steel tube outside, which can be regarded as a combination of square CFST and SRC. An X shape section steel is commonly used as the inner section steel. Since the outside steel tube can provide effective confinement to core steel reinforced concrete, no additional steel reinforcement is needed for this composite column. Self-consolidating concrete (SCC) or self-compacting concrete can be commonly used as core concrete in the steel tube. The design of SRSCFSHS column is an attempt to combine the advantages of SRC and CFST columns, so as to achieve better composite effect for higher load carrying capacity and better ductility.

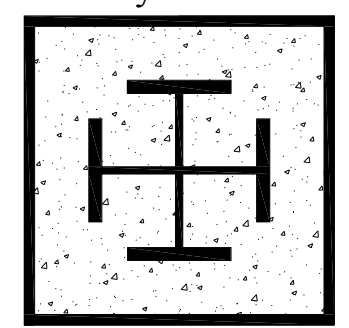

Figure 1. Cross Section of a SRSCFSHS Column

In recent years, some researchers have conducted experimental studies on the mechanical behaviors of SRSCFSHS columns subjected to compressive loading. Zhu et al. [14] finished a series of tests to study compressive behaviors of square steel tubular columns filled with steel reinforced self-consolidating high strength concrete. The experimental results indicated that the encased section steel could restrain the generation or propagation of diagonal shear cracks in core concrete, and could change the failure mode and the post-yield behavior of short composite columns. Wang et al. [15] conducted experimental investigation and theoretical analysis of SRSCFSHS columns subjected to eccentric loading. The experimental results indicated that the increment of eccentricity ratio led to decrease of both load carrying capacity and initial stiffness of the composite columns, and the increase of steel-reinforced ratios could result in gradual improvement of the load carrying capacity and the initial stiffness. Based on theory of the limited strip unit method, Zhao [16] developed a nonlinear analysis on the compression-bending behavior of SRSCFSHS columns. As for the design codes, a formula was proposed to calculate the load carrying capacity of SRSCFSHS columns in Eurocode 4 [17]. It is found that the confinement effect of outer steel tube on core concrete was not considered, as well as the interaction between concrete and section steel, indicating the model in Eurocode 4 may comparatively underestimate the load carrying capacity of the SRSCFSHS columns. Meanwhile, due to the scale and equipment limitation, few researches have been conducted to reveal the composite effect and failure mechanisms of full-size SRSCFSHS columns under uniaxial compression.

Set against the above background, this study aims to investigate the mechanical behaviors of SRSCFSHS columns subjected to uniaxial compressive loading and propose a reliable model for predicting the ultimate bearing capacity of SRSCFSHS columns. For the SRSCFSHS column shown in Figure1, an X shape section steel were embedded in the center of a square CTST column. 
The ABAQUS/standard solver was employed to numerically study the mechanical behaviors of SRSCFSHS columns under uniaxial load. Existing experimental work on SRSCFSHS columns conducted by Zhu [14] were utilized to verify the proposed finite element model and the adopted methodology. Then, an extensive parametric study on different parameters including steel tube ratio $\left(\alpha_{t}\right)$, section steel ratio $\left(\alpha_{\mathrm{S}}\right)$, the strength of the core concrete $\left(f_{\mathrm{C}}\right)$, the yield strength of steel tube $\left(f_{\mathrm{y}}^{\mathrm{t}}\right)$, the yield strength of section steel $\left(f_{\mathrm{y}}^{\mathrm{s}}\right)$ and the slenderness ratio $(\lambda)$, was carried out. Subsequently, a comparison between SRSCFSHS and its components was also made in terms of the mechanical behaviors and failure mode. Then, the calculation model in Eurocode 4 was used to calculate the strengths of the simulated SRSCFSHS columns. Owing to the fact that the current European Code has not yet included an accurate equation to evaluate the load carrying capacity of the SRSCFSHS, a novel model was then proposed.

\section{VERIFICATION OF FINITE ELEMENT MODEL OF SRSCFSHS COLUMNS}

\subsection{Constitutive Models of Materials}

Finite element analysis (FEA) is a theoretical tool which has been widely used in the analysis of steel composite structures [18-19]. In this study, the nonlinear finite element analysis was conducted to simulate the mechanical behaviors of SRSCFSHS columns with the software of ABAQUS [20]. The steel tube and the section steel are modeled as isotropic elastic-plastic materials in the finite element model. For both the steel tube and section steel, a five-stage stress-strain model [21] is used to describe the uniaxial stress-strain relationship, which is shown in Figure2 and given by:

$$
\begin{aligned}
& \sigma_{s}=\left\{\begin{array}{cl}
E_{s} \varepsilon_{s} & \varepsilon_{s}<\varepsilon_{e} \\
-A \varepsilon_{s}^{2}+B \varepsilon_{s}+C & \varepsilon_{e}<\varepsilon_{s} \leq \varepsilon_{e 1} \\
f_{y} & \varepsilon_{e 1}<\varepsilon_{s} \leq \varepsilon_{e 2} \\
f_{y}\left[1+0.6 \frac{\varepsilon_{s}-\varepsilon_{e 2}}{\varepsilon_{e 3}-\varepsilon_{e 2}}\right] & \varepsilon_{e 2}<\varepsilon_{s} \leq \varepsilon_{e 3} \\
1.6 f_{y} & \varepsilon_{s}>\varepsilon_{e 3}
\end{array}\right. \\
& \text { where } \\
& \varepsilon_{e}=0.8 f_{y} / E_{S}, \varepsilon_{e 1}=1.5 \varepsilon_{e}, \quad \varepsilon_{e 2}=10 \varepsilon_{e 1}, \varepsilon_{e 3}=100 \varepsilon_{e 1}, A=0.2 f_{y} /\left(\varepsilon_{e 1}-\varepsilon_{e}\right)^{2}, B=2 A \varepsilon_{e 1}, C=0.8 f_{y}+A \varepsilon_{e}{ }^{2}-B \varepsilon_{e}
\end{aligned}
$$

In order to simulate the plastic behaviour of core concrete in SRSCFSHS columns under compression, the three-stage stress-strain relationship shown in Figure3 was adopted [22]. This model is illustrated as following:

In the initial stage (from Point $\mathrm{O}$ to Point $\mathrm{A}$ in Figure 3), there is no or very little interaction between the steel tube and concrete. Therefore, the ascending branch of the stress-strain relationship of unconfined concrete is given by:

where

$$
\begin{gathered}
\frac{\sigma}{f_{c}^{\prime}}=\frac{A X+B X^{2}}{1+(A-2) X+(B-1) X^{2}} \quad 0<\varepsilon \leq \varepsilon_{c 0} \\
\mathrm{X}=\frac{\varepsilon}{\varepsilon_{c 0}} ; \mathrm{A}=\frac{E_{c} \varepsilon_{c 0}}{f_{c}^{\prime}} ; \mathrm{B}=\frac{A-1^{2}}{0.55}-1 ; \varepsilon_{c 0}=0.00076+\sqrt{\left(0.626 f_{c}^{\prime}-4.33\right) \times 10^{-7}}
\end{gathered}
$$


In the second stage, a plateau (from Point A to Point B) is included to represent the increased peak strain of concrete due to confinement. The strain at Point B $\left(\varepsilon_{c c}\right)$ can be expressed as following:

$\frac{\varepsilon_{c c}}{\varepsilon_{c 0}}=e^{k} \quad \varepsilon_{c 0}<\varepsilon \leq \varepsilon_{c c}$
where k=(2.9224-0.00367f $\left.f_{c}^{\prime}\right)\left(\frac{f_{B}}{f_{c}^{\prime}}\right)^{0.3124+0.002 f_{c}^{\prime}} ; f_{\mathrm{B}}=\frac{0.25\left(1+0.027 f_{y}\right) \mathrm{e}^{\frac{-0.028 \mathrm{~B}}{\mathrm{t}}}}{1+1.6 \mathrm{e}^{-10}\left(f_{c}^{\prime}\right)^{4.8}}$.

For the descending branch of the model (BC) shown in Figure 3, an exponential function was used, which is defined by:

$$
\sigma=0.1 f_{c}^{\prime}+0.9 f_{c}^{\prime} \exp \left[-\left(\frac{\varepsilon-\varepsilon_{c c}}{\alpha}\right)^{0.92}\right] \quad \varepsilon \geq \varepsilon_{c c}
$$

where $\alpha=0.005+0.0075 \xi_{c} ; \xi_{c}=\frac{A_{s} f_{y}}{A_{c} f_{c k}}$, respectively.

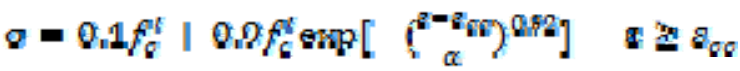

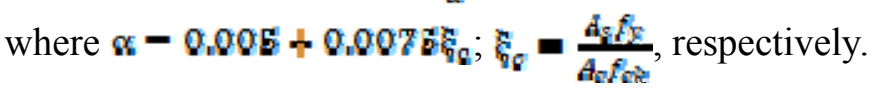

In the above formula $A_{s}$ and $A_{c}$ are the cross-sectional areas of steel tube and concrete respectively, $f_{\varepsilon}^{\prime}$ is the cylinder strength of concrete, $f_{c k}$ is the characteristic strength of concrete, $F_{S}$ is the Elastic modulus of steel and $f_{\gamma}$ is the yield strength of steel tube. The elastic modulus of concrete $\left(E_{C}\right)$ is taken as $4730, F_{R}$ according to ACI 318-11[23], and the Poisson's ratio of concrete is taken as 0.2. A fracture energy model proposed by Hillerborg et al. [24] is used to simulate the tensile-soften behavior of concrete.

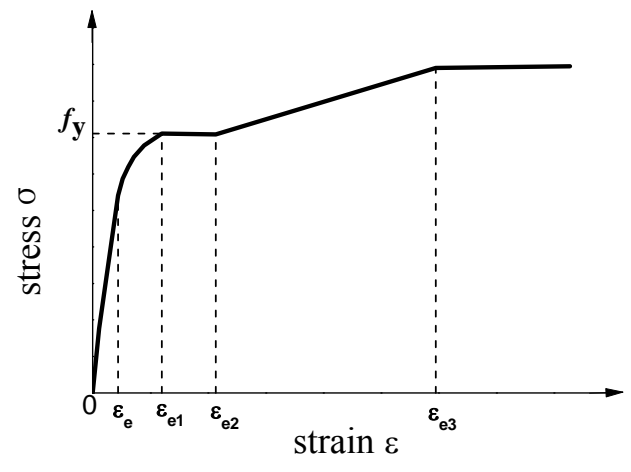

Figure 2. Typical $\sigma-\varepsilon$ curve for steel

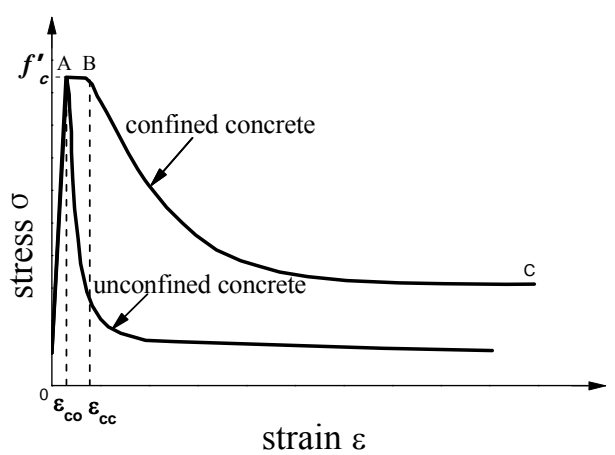

Figure 3. Typical $x-\varepsilon$ curves for concrete

\subsection{Description of Finite Element Model of SRSCFSHS Column}

To achieve identical vertical deformations for the entire cross section, two steel end plates were used at both the top and bottom of the SRSCFSHS column in the finite element model. Herein, for each specimen, there are five individual components including outer square steel tube, section steel, core concrete, top and bottom end plates. The interactions between these components were defined by contact surfaces, where one surface acted as the master surface and the other as the slave surface. 
The difference between a master and a slave surface lies in that the former can penetrate the latter, but the reverse cannot take place. Core concrete was defined as the slave surface since it contacted with both the end plates and the steel tube, while the steel tube were treated as the slave surface for its contact with the end plates. "Tie contact" was defined for the contact between the end plate and the steel tube, which ensures the contact elements have the same displacements and rotational angles during the loading process. The contact between the end plate and concrete was defined as "hard contact", meaning that no contact pressure occurs unless one surface contacts another, and the contact surfaces were allowed to separate from each other after they contacted. "Hard contact" was also used to define the contact between steel tube and core concrete in the normal direction. The Mohr-Coulomb friction model was applied in the tangential direction for the contact between steel tube and core concrete while the friction coefficient is set to be 0.25 [4]. Since the section steel was embedded in the core of the CFST column, the "Tie contact" constraint was used to describe the contact between concrete and section steel. The slip between core concrete and section steel was neglected.

The bottom end plate was fixed against all degrees of freedom whereas the top plate was able to deform along the longitudinal axis (in the direction of $\mathrm{z}$ coordinate). The uniaxial compressive load was applied on the top plate by displacement increments. A mesh convergence study was performed to identify an appropriate mesh density for achieving reliable results. In the FEA model of the SRSCFSHS column, the steel tube was simulated by four-node conventional shell element (SR4) while the section steel, the end plates and core concrete were modelled by 3D eight-node solid elements with reduced integration (C3D8R). Figure 4 shows the meshing configurations of the SRSCFSHS column and its components.

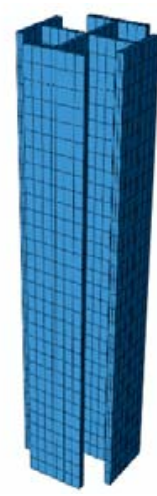

(a) Section steel

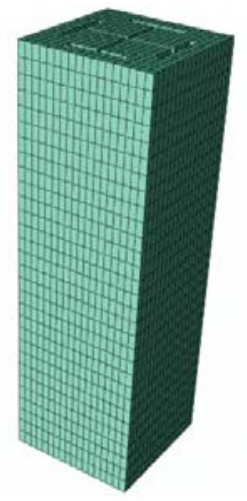

(b) Core concrete

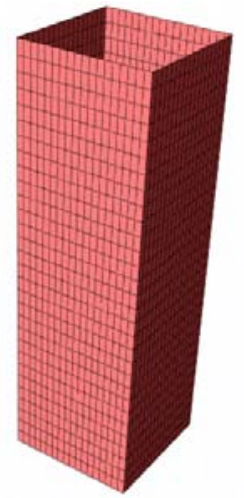

(c) Steel tube

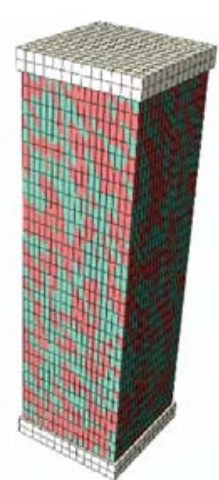

(d) SRSCFSHS

Figure 4. Meshing and Configuration of the SRSCFSHS Column Model

\subsection{Verification of the Proposed Finite Element Model}

To verify the validity of the FEA model described above, existing experiments conducted by Zhu et al. [14] were selected and analyzed with the proposed FE models. A total of four SRSCFSHS columns from the tests were numerically studied, and the dimensions and material properties of the columns are shown in Table 1. Figure 5 shows axial load $(\mathrm{L})$ versus average axial strain $(\varepsilon)$ curves of the SRSCFSHS columns from both the experimental and simulation results. As can be seen in Table 1, the maximum error of load carrying capacity was less than $8 \%$. Generally, the simulation results are in good agreement with the experimental results, indicating that the proposed finite element models of the SRSCFSHS columns are valid. 
Table 1. Dimensions and Material Properties of the SRSCFSHS Columns

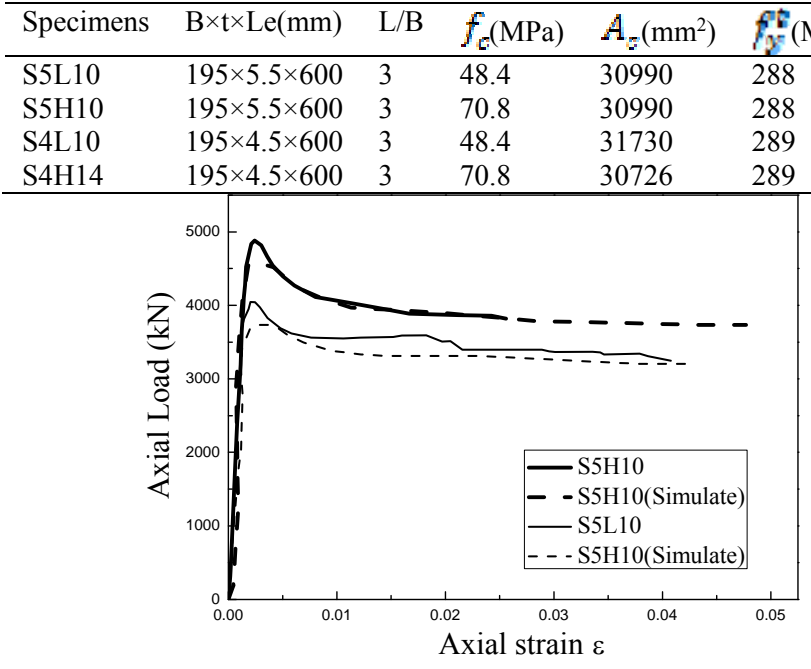

(a) for S5L10, S5H10

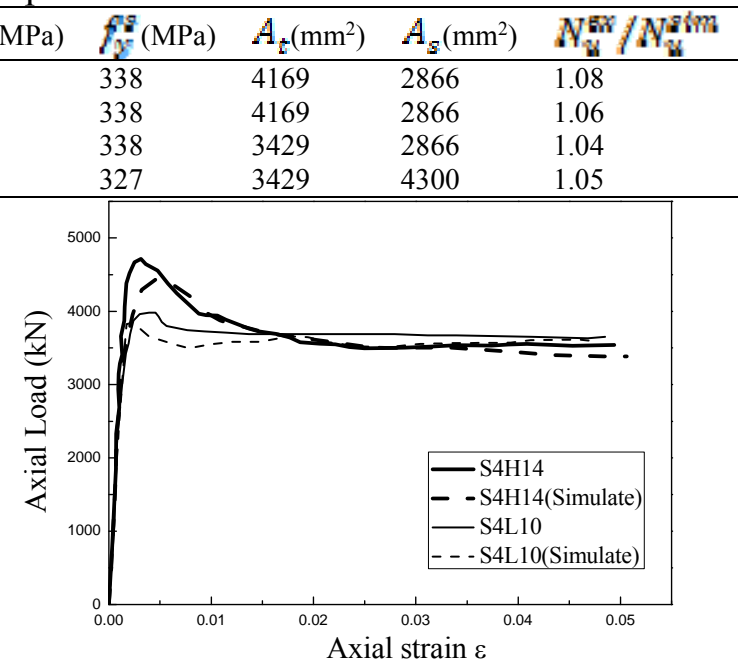

(b) for S4L10, S4H14

Figure 5. Axial Load-average Axial Strain Curves from Both Experiments and FE Analysis

\section{MECHANICAL BEHAVIORS OF SRSCFSHS COLUMNS IN UNIAXIAL COMPRESSION}

In this section, the simulation results of a typical specimen S4H14 were employed to discuss the failure mode and mechanical behavior of the SRSCFSHS columns.

\subsection{Failure Mode}

The typical failure modes of SRSCFSHS components are shown in Figure 6. It is found that the failure mode of SRSCFSHS column is quite similar to normal CFST columns. In the final stage, outward local bulking is observed in the middle of the steel tube, while inward bucking is avoided due to the support from steel reinforced core concrete. For the embedded section steel, no local buckling is observed due to ambient complete support from steel tube confined core concrete. In the ultimate stage, outward bulge occurs in the middle of the SRSCFSHS column. The transverse deformation of concrete in the region close to the two ends is smaller than that of concrete in the middle of the column, which is due to constraint of transverse deformation caused by the end steel plates.

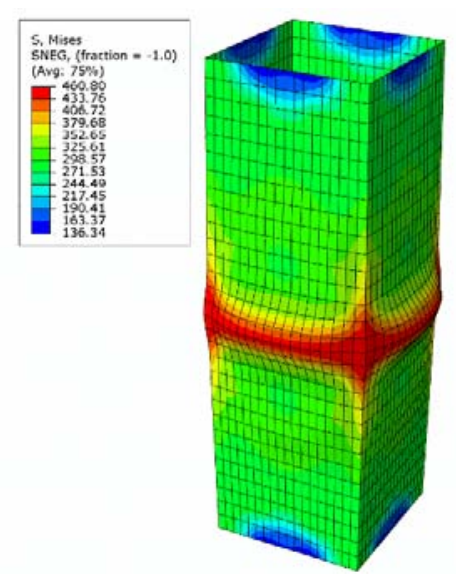

(a) Steel tube

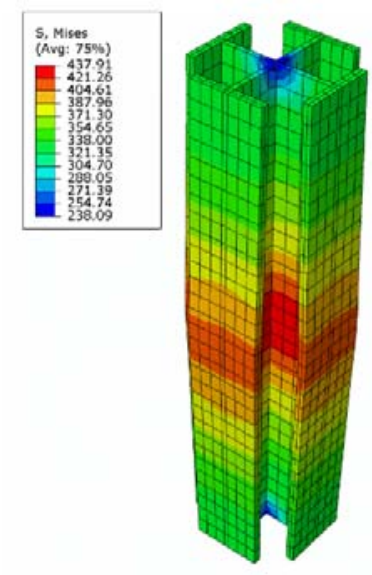

(b) Section steel

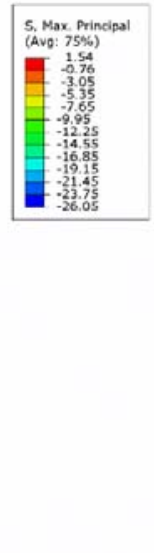

(c) Core concrete

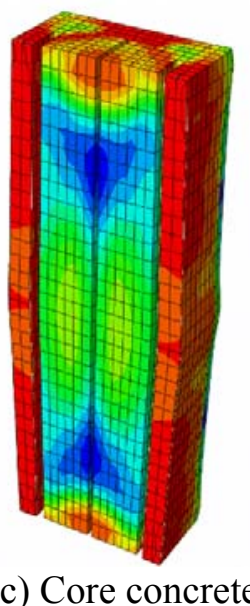

Figure 6. Typical failure mode of the components of the SRSCFSHS column 


\subsection{Axial Load Versus Average Axial Strain Curves}

The calculated axial load (L) versus axial strain ( $\varepsilon$ ) curve of the SRSCFSHS column is shown in Figure 7. The axial load (L) versus axial strain ( $\mathrm{z}$ ) curves of the components including core concrete, steel tube, section steel are also shown in Figure7. Four characteristic points are marked on the curve of the SRSCFSHS column. Point A defines the moment when the steel tube begins to yield. Point B indicates the moment when core concrete just reaches the peak strength. Point $\mathrm{C}$ indicates the section steel reaches the peak strength, and Point D defines the final failure of the composite column due to large deformation. Thus, the L versus $\varepsilon$ curve of the SRSCFSHS column can be generally divided into four stages. In the first stage (OA), the composite column generally shows elastic behavior. At Point A, the stress of core concrete and section steel are about $80 \%$ and $70 \%$ of their peak strength, respectively. In the second stage (AB), the average axial strain $(\varepsilon)$ increases more quickly than that in the first stage. At Point $\mathrm{B}$, while the core concrete just reaches its peak strength, the steel tube has entered the plastic stage. In this stage, the maximum stress of the section steel is about $80 \%$ of its peak strength. The column approaches its peak strength at the end of the stage. The segment of BC defines the third stage of the axial load-average axial strain curves. In this stage, the stress of the column and the core confined concrete decreases with further axial deformation even though the stress of the section steel continues to increase. At Point $\mathrm{C}$ the section steel reaches its peak strength, which is later than the composite column yields (point B), indicating the section steel can provide "strength reserve" and can increase the post-yielding strength of the composite column. This also has a significant benefit for the fire resistance of the SRSCFSHS column. In the last stage (CD), the load almost keeps stable with increasing axial deformation. In this stage, the core concrete sustains about $50 \%$ of the strength of the composite column, while the steel tube and section steel sustain the remaining $50 \%$ of the strength. The composite column finally fails by excessive axial and transverse deformation due to the yielding of steel tube and section steel as well as the nonlinear deformation of core confined concrete.

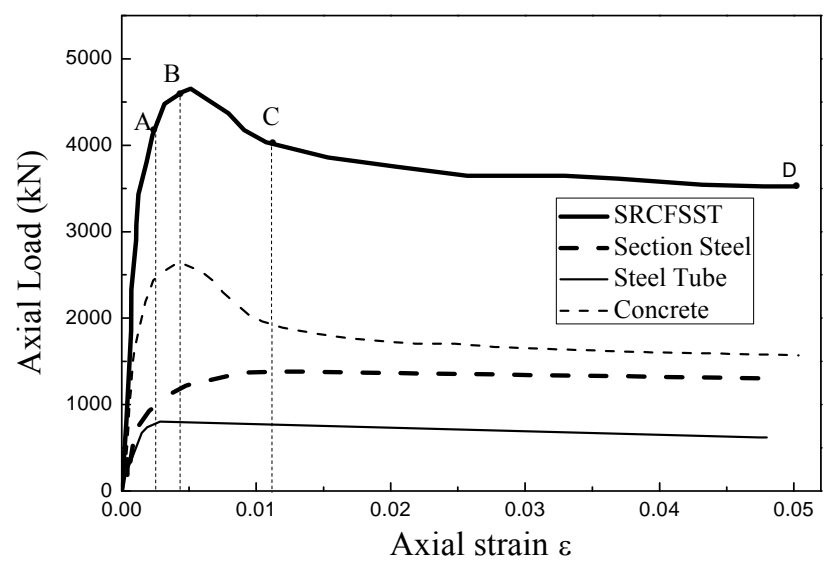

Figure 7. Typical Axial Load (L) Versus Axial Strain ( $\varepsilon$ ) Response of SRSCFSHS Column

\subsection{Comparison of Mechanical Behavior between SRSCFSHS Column and Its components}

In order to analyze the composite effects of the components in SRSCFSHS columns, the mechanical behaviors of individual CFST and section steel are also numerically simulated. 


\subsubsection{Comparison between section steel in SRSCFSHS column and single section steel}

The comparison of mechanical behavior between section steel in SRSCFSHS column and single section steel under uniaxial compression is shown in Figure 8. In order to simulate the performance of single section steel under uniaxial compression, nonlinear buckling analysis method provided by ABAQUS was applied in this paper [20]. The section steel in the SRSCFSHS column fails due to compression yielding, while the individual section steel fails by buckling in the middle of the length under uniaxial compression, as shown in Figure 9. According to the calculation results, the load carrying capacity of the section steel in the composite column is $40 \%$ higher than that of the individual section steel. This is due to the fact that the inner section steel is under the confinement of the square CFST, while the individual section steel has no support from the surrounding concrete and local buckling occurs under axial loading.

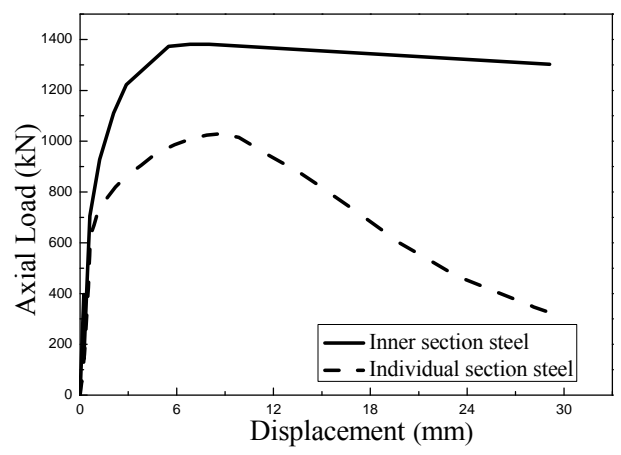

Figure 8. Comparison of Mechanical Behavior between Inner Section Steel and Individual Section Steel
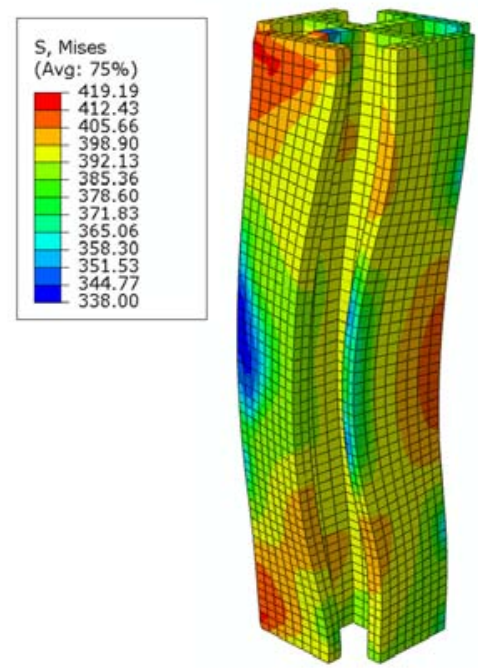

Figure 9. Failure Mode of Single Section Steel

\subsubsection{Comparison between SRSCFSHS Column and Square CFST Column}

Figure10 is depicted to illustrate the L- $\varepsilon$ curves of the SRSCFSHS column and the individual CFST column. It should be noticed that the CFST column has the same cross-section and the material properties as the SRSCFSHS column except that there is no section steel embedded in the CFST column. According to the simulation results, the load carrying capacity of the SRSCFSHS column is about $28 \%$ higher than that of the individual CFST column due to the existence of the 
section steel. After the peak load, the L- $\varepsilon$ curve of the SRSCFSHS column drops more gradual than that of the individual CFST column. This is due to the fact that the section steel can provide "strength reserve" for the SRSCFSHS column. In order to compare the ductility of SRSCFSHS and CFST columns, the ductility coefficient (u) was introduced which can be calculated as $u=a_{w} / a_{y}$, where $\varepsilon_{u}$ is the ultimate strain and $\varepsilon_{y}$ is the yield strain. As can be seen in Figure11, $\boldsymbol{s}_{u}$ is equal to the strain corresponding to a $15 \%$ drop of the peak load in the descending part of L- $\varepsilon$ curves, while $s_{y}$ is calculated according to the criteria for equivalent elastoplastic yield [25]. The ductility coefficients of the two columns are presented in Table 2. It can be seen that the ductility coefficient of SRCFST column is about $80 \%$ higher than that of CFST column.

Figure 12 shows the maximum principal plastic strain of core concrete for both SRSCFSHS column and CFST column. The maximum principal plastic strain can be regarded as the cracking of concrete in FEA model and the cracks are perpendicular to the orientation of the maximum principal plastic strain. It can be seen that maximum principal plastic strain of SRSCFSHS column is much lower than that of CFST columns. The outward deformation of core concrete in SRSCFSHS column is much smaller than that of core concrete in the CFST column. Especially, for the CFST column, the outward deformation almost concentrates in the middle of the edge. Concrete cracks can be represented by the maximum principal plastic strain and the cracks are perpendicular to the orientation of the maximum principal plastic strain. Therefore, according to Figure12, the encased section steel can effectively restrain the generation or propagation of cracks in the core concrete.

Figure 13 shows the distribution of contact pressure between core concrete and square steel tube for both SRSCFSHS and CFST columns. Contact pressure can reflect the confinement of steel tube to core concrete. For a certain cross section, the contact pressure concentrates at the corner areas of both SRSCFSHS column and CFST column. Along the length of columns, the contact pressure of SRSCFSHS column is higher than that of CFST column. The contact pressure of SRCFST column distributes uniformly along the edges, while the contact pressure of CFST column generally concentrates in the middle part of the edges.

According the aforementioned analysis, the cracks in core concrete of SRSCFSHS column are restrained due to the existence of section steel, thus the contact pressure between the square steel tube and core concrete distributes more uniformly and better composite effects can be achieved. Therefore, the SRCFST columns have both higher load carrying capacity and ductility than the square CFST columns.

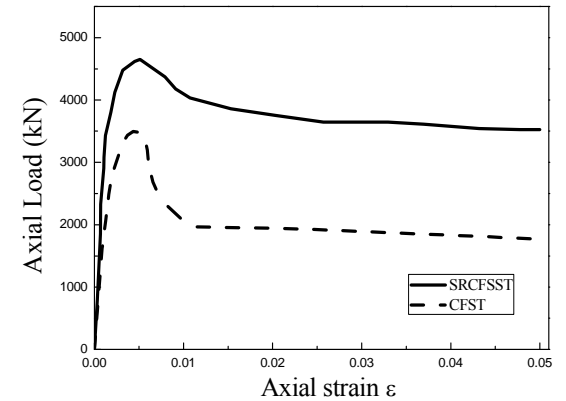

Figure 10. L- $\varepsilon$ Curves of SRSCFSHS and CFST

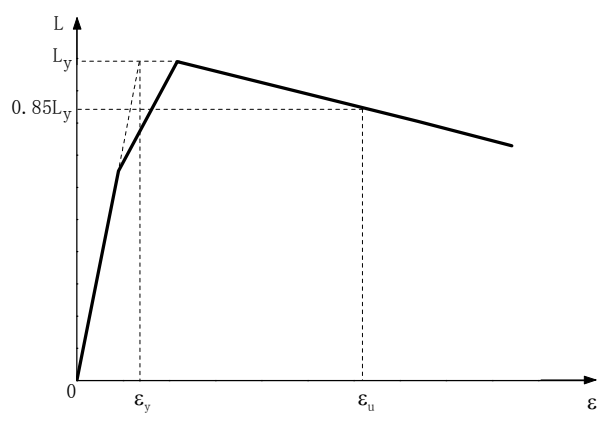

Figure 11. Definition of Ductility Coefficient 
Table 2. Ductility Coefficients of SRSCFSHS and CFST Columns

\begin{tabular}{ccc}
\hline Coefficients & SRSCFSHS & CFST \\
\hline$\varepsilon_{u}$ & 0.018 & 0.008 \\
$\varepsilon_{y}$ & 0.002 & 0.0016 \\
$\mathrm{u}$ & 9 & 5 \\
\hline
\end{tabular}

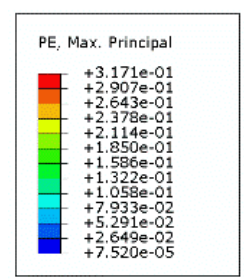

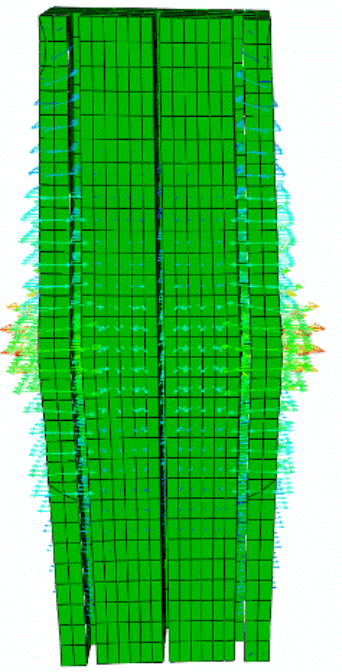

(a) For SRSCFSHS column

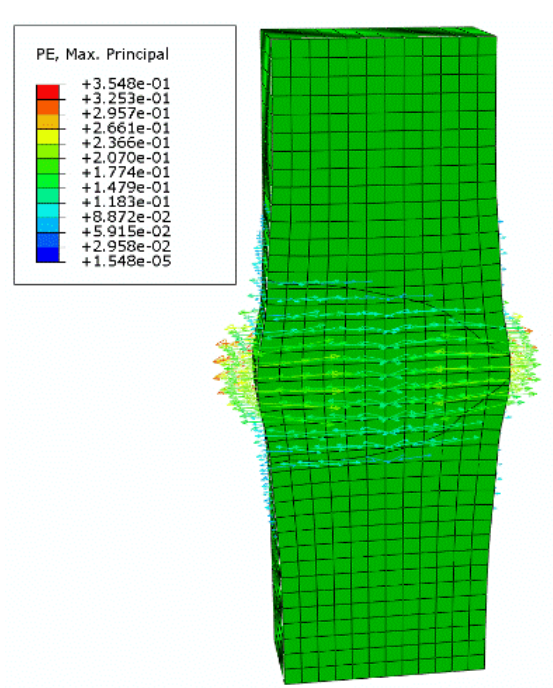

(b) For CFST column

Figure 12. Maximum Principal Plastic Strain of Core Concrete

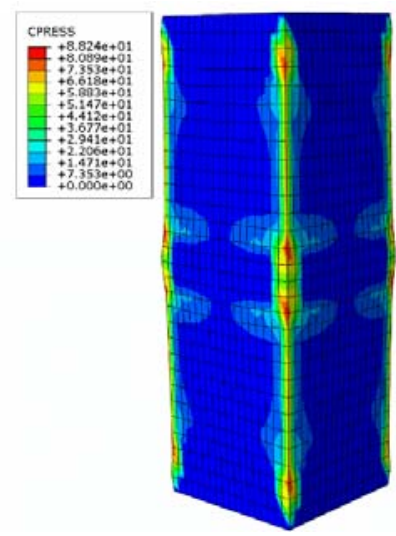

(a) For SRSCFSHS column
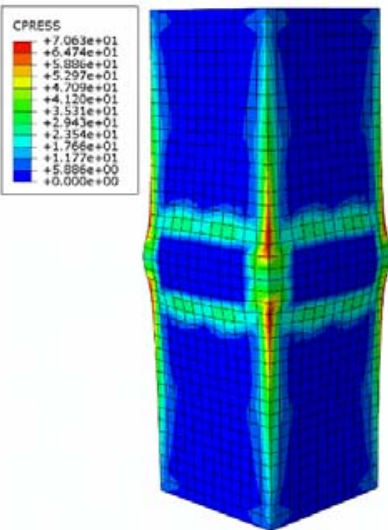

(b) For CFST column

Figure 13. Contact Pressure of Core Concrete

\section{PARAMETRIC STUDY}

In this section, a total of 26 SRSCFSHS columns were analyzed to study the effect of the dimensions and material properties on the mechanical behaviors of the composite columns. Table 3 summarizes the characteristics of the SRSCFSHS columns in the parametric study.

\subsection{Effect of Section Steel Strength}

According to the simulation results in Figure 14, increasing section steel strength $\left(f_{\gamma}\right)$ leads to gradual increase of the peak strength and the initial stiffness as well as the residual strength of SRSCFSHS columns. For the cases with different strengths of section steel, the shapes of the L- $\varepsilon$ 
curves are quite similar and the curves are almost parallel to each other after the peak strength, and the influence of section steel strength $\left(y_{y}\right)$ on the ductility of SRSCFSHS columns is not significant.

Table 3. Dimensions and Material Properties of Circular SRSCFSHS in the Parametric Study

\begin{tabular}{|c|c|c|c|c|c|c|c|c|c|c|}
\hline \multirow[t]{2}{*}{ Group } & \multirow[t]{2}{*}{ Specimens } & \multicolumn{7}{|c|}{ Dimensions } & \multicolumn{2}{|c|}{ Material properties } \\
\hline & & $\mathrm{L}_{0} \times \mathrm{B} \times \mathrm{t}$ & $\lambda$ & $A_{\varepsilon}$ & $A_{z}$ & $\alpha_{t}$ & $\alpha_{g}$ & $f_{c u}(\mathrm{MPa})$ & $f(\mathrm{MPa})$ & $f^{\prime}(\mathrm{MPa})$ \\
\hline \multirow[t]{4}{*}{1 (SS) } & SS-1 & $600 \times 195 \times 4.5$ & 10.6 & 3429 & 2866 & 0.11 & 0.09 & 70.8 & 235 & 345 \\
\hline & SS-2 & $600 \times 195 \times 4.5$ & 10.6 & 3429 & 2866 & 0.11 & 0.09 & 70.8 & 345 & 345 \\
\hline & SS-3 & $600 \times 195 \times 4.5$ & 10.6 & 3429 & 2866 & 0.11 & 0.09 & 70.8 & 390 & 345 \\
\hline & SS-4 & $600 \times 195 \times 4.5$ & 10.6 & 3429 & 2866 & 0.11 & 0.09 & 70.8 & 420 & 345 \\
\hline \multirow[t]{4}{*}{$2(\mathrm{CS})$} & CS-1 & $600 \times 195 \times 4.5$ & 10.6 & 3429 & 2866 & 0.11 & 0.09 & 30 & 235 & 345 \\
\hline & $\mathrm{CS}-2$ & $600 \times 195 \times 4.5$ & 10.6 & 3429 & 2866 & 0.11 & 0.09 & 40 & 235 & 345 \\
\hline & $\mathrm{CS}-3$ & $600 \times 195 \times 4.5$ & 10.6 & 3429 & 2866 & 0.11 & 0.09 & 50 & 235 & 345 \\
\hline & CS-4 & $600 \times 195 \times 4.5$ & 10.6 & 3429 & 2866 & 0.11 & 0.09 & 60 & 235 & 345 \\
\hline \multirow[t]{4}{*}{ 3(TS) } & TS-1 & $600 \times 195 \times 4.5$ & 10.6 & 3429 & 2866 & 0.11 & 0.09 & 70.8 & 235 & 235 \\
\hline & TS-2 & $600 \times 195 \times 4.5$ & 10.6 & 3429 & 2866 & 0.11 & 0.09 & 70.8 & 235 & 345 \\
\hline & TS-3 & $600 \times 195 \times 4.5$ & 10.6 & 3429 & 2866 & 0.11 & 0.09 & 70.8 & 235 & 390 \\
\hline & TS-4 & $600 \times 195 \times 4.5$ & 10.6 & 3429 & 2866 & 0.11 & 0.09 & 70.8 & 235 & 420 \\
\hline \multirow[t]{5}{*}{$4(\mathrm{TR})$} & TR-1 & $600 \times 195 \times 3$ & 10.6 & 2286 & 2866 & 0.11 & 0.09 & 70.8 & 235 & 345 \\
\hline & TR-2 & $600 \times 195 \times 6$ & 10.6 & 4572 & 2866 & 0.15 & 0.09 & 70.8 & 235 & 345 \\
\hline & TR-3 & $600 \times 195 \times 9$ & 10.6 & 6858 & 2866 & 0.22 & 0.09 & 70.8 & 235 & 345 \\
\hline & TR-4 & $600 \times 195 \times 12$ & 10.6 & 9144 & 2866 & 0.29 & 0.09 & 70.8 & 235 & 345 \\
\hline & TR-5 & $600 \times 195 \times 15$ & 10.6 & 11430 & 2866 & 0.37 & 0.09 & 70.8 & 235 & 345 \\
\hline \multirow[t]{5}{*}{$5(\mathrm{SR})$} & SS-1 & $600 \times 195 \times 4.5$ & 10.6 & 3429 & 2866 & 0.11 & 0.09 & 70.8 & 235 & 345 \\
\hline & SS-2 & $600 \times 195 \times 4.5$ & 10.6 & 3429 & 3622 & 0.11 & 0.12 & 70.8 & 235 & 345 \\
\hline & SS-3 & $600 \times 195 \times 4.5$ & 10.6 & 3429 & 4304 & 0.11 & 0.14 & 70.8 & 235 & 345 \\
\hline & SS-4 & $600 \times 195 \times 4.5$ & 10.6 & 3429 & 5230 & 0.11 & 0.17 & 70.8 & 235 & 345 \\
\hline & SS-5 & $600 \times 195 \times 4.5$ & 10.6 & 3429 & 6124 & 0.11 & 0.20 & 70.8 & 235 & 345 \\
\hline \multirow[t]{4}{*}{$5(\mathrm{SL})$} & SL-1 & $564 \times 195 \times 4.5$ & 10 & 3429 & 2866 & 0.11 & 0.09 & 70.8 & 235 & 345 \\
\hline & SL-2 & $1127 \times 195 \times 4.5$ & 20 & 3429 & 2866 & 0.11 & 0.09 & 70.8 & 235 & 345 \\
\hline & SL-3 & $2816 \times 195 \times 4.5$ & 50 & 3429 & 2866 & 0.11 & 0.09 & 70.8 & 235 & 345 \\
\hline & SL-4 & $5635 \times 195 \times 4.5$ & 100 & 3429 & 2866 & 0.11 & 0.09 & 70.8 & 235 & 345 \\
\hline
\end{tabular}

\subsection{Effect of Core Concrete Strength}

According to the simulation results in Figure 15, increasing the strength of core concrete $\left(f_{c u}\right)$ can result in improvement in the peak strength and the residual strength of SRSCFSHS columns. Since the deformation capacity of the composite column is governed by the deformation ability of the steel tube and section steel, all SRSCFSHS columns show high ductility. However, as the concrete strength increases from $30 \mathrm{MPa}$ to $60 \mathrm{MPa}$, the increase of the ultimate strength is much smaller than that of the peak strength, indicating the strength of core concrete has little effect on the ultimate strength of SRSCFSHS column. This is due to the fact that the increase of concrete strength may lead to higher brittleness, and high strength concrete softens significantly and can sustain similar external load to low strength concrete in the ultimate stage. 


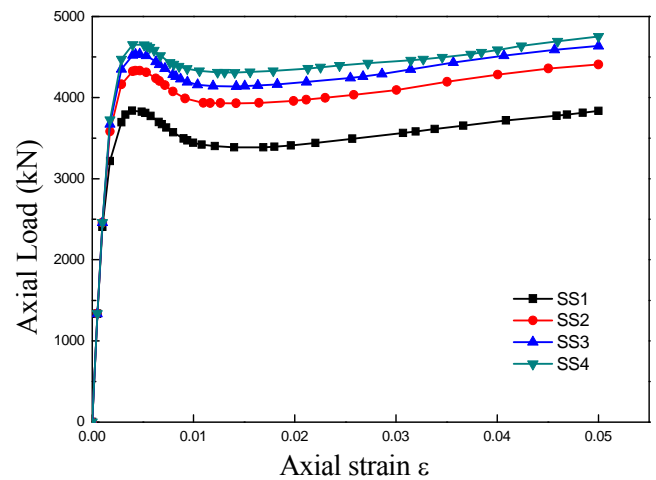

Figure 14. Effect of Section Steel Strength

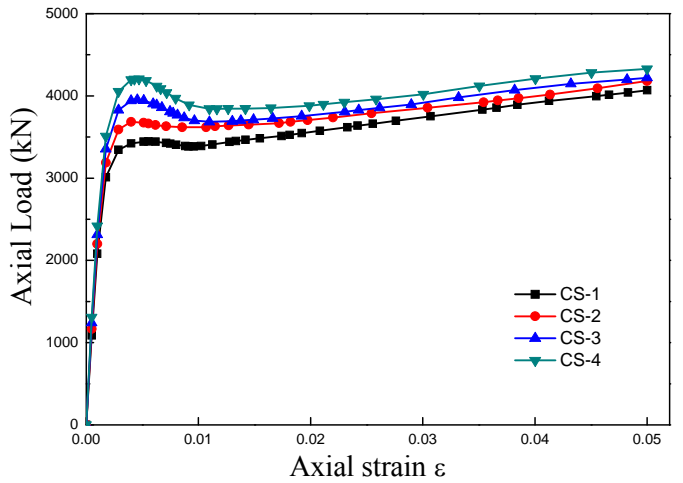

Figure 15. Effect of Concrete Strength

\subsection{Effect of Steel Tube Strength}

Figure 16 shows the effect of steel tube strength $\left(f_{\gamma}\right)$ on the mechanical behavior of the SRSCFSHS column. It can be seen that the curves become smoother with the increase of steel tube strength after the peak strength. From one hand, the increase of steel tube strength can certainly increase the bearing capacity of the steel tube. From the other hand, increasing the strength of steel tube can provide more effective confinement to core concrete, resulting in improvement of bearing capacity of the core concrete. Therefore, increasing steel tube strength can both increase the peak strength and the ultimate strength of the composite SRSCFSHS column.

\subsection{Effect of Steel Tube Ratio}

Steel tube ratio $\left(\alpha_{t}\right)$ is an important factor that affects the axial compression behavior of SRSCFSHS columns. The steel tube ratio is defined as $\alpha_{i}=A_{3} / A_{0}$, where $A_{t}$ represents the area of steel tube and $A_{c}$ represents the area of core concrete. According to the simulation results in Figure 17, increasing steel tube ratio $\left.\alpha_{t}\right)$ can lead to significant increase of the peak strength or the ultimate strength of SRSCFSHS column. With increasing steel tube ratio, the SRSCFSHS columns exhibited various post-yield behaviors. Specimen TR-1 shows softening behavior, while TR-5 exhibits strain hardening behavior in the post-yield stage, which is due to the fact that increasing the ratio of steel tube can significantly improve the confinement to core concrete and result in the change from strength softening behavior to strength or strain hardening behavior of the SRSCFSHS column.

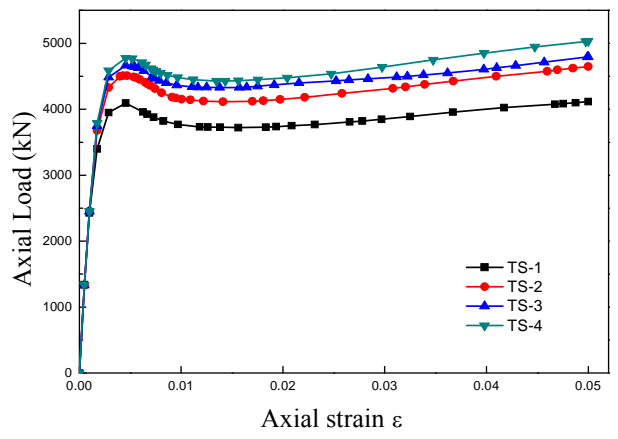

Figure 16. Effect of Steel Tube Strength

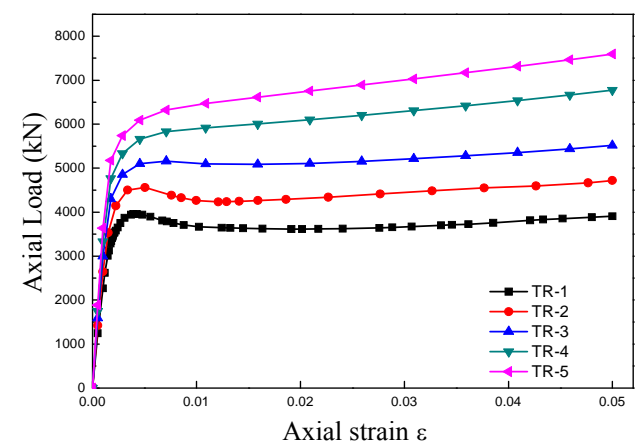

Figure 17. Effect of Steel Tube Ratio

\subsection{Effect of Section Steel Ratio}

The section steel ratio is defined as $\alpha_{g} \boldsymbol{m} \mathrm{A}_{g} / \mathrm{A}_{\mathrm{g}}$, where $\mathrm{A}_{g}$ represents the area of section steel and $A_{u}$ represents the area of core concrete. Figure18 shows the effect of section steel ratio $\left(\alpha_{y}\right)$ on the 
axial compression behavior of SRSCFSHS columns. The shapes of the curves are very similar, and the peak strength and the ultimate strength of the composite column increase with significantly with the section steel ratio, indicating increasing the section steel ratio is an effective way to enhance peak strength or ultimate strength of the SRSCFSHS columns.

\subsection{Effect of Slenderness Ratio}

The slenderness ratio $(\lambda)$ of SRSCFSHS columns is defined as $\lambda-L_{0} / t$, where $L_{0}$ is the effective column length, $i$ is radius of gyration. The initial out-of-straightness is the main factor that influence the compression behavior of slender columns. In this study, the out-of-straightness is taken as L/5000 [26]. The compression behavior of SRSCFSHS column can be discussed with the

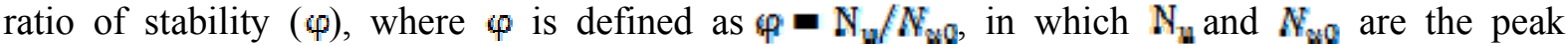
strength and the sectional strength of the composite column. The schematic view of $q-A$ relation is shown in Figure20. Figure19 shows the effect of slenderness ratio $(\lambda)$ on the axial compression behavior of SRSCFSHS columns. The shapes of curves are quite different even though they have same cross section and material properties. Generally, specimen SL-1 can be classified as strength failure, SL-2, SL-3 can be classified as elastic-plastic instability failure while SL-4 can be classified as elastic instability failure. The typical $\varphi-\lambda$ relation of SRSCFSHS column is shown in Figure21. It can be seen that the SRSCFSHS column shows strength failure mode when $A \mathbb{A} 15$, and shows elastic-plastic instability failure mode when $15 \mathrm{~m}, \lambda \mathbf{3}$ and shows elastic instability failure mode when $\lambda$ s. 6 .

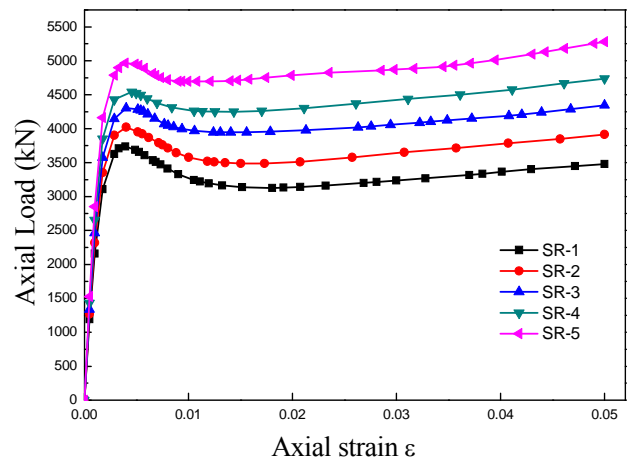

Figure 18. Effect of Section Steel Ratio

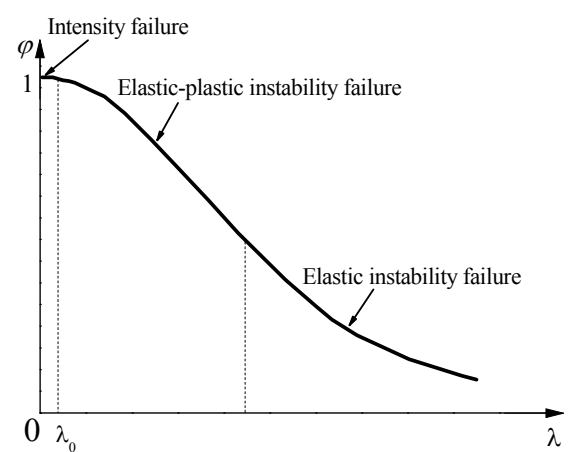

Figure 20. Schematic View of $\varphi_{p}-\lambda$ Relation

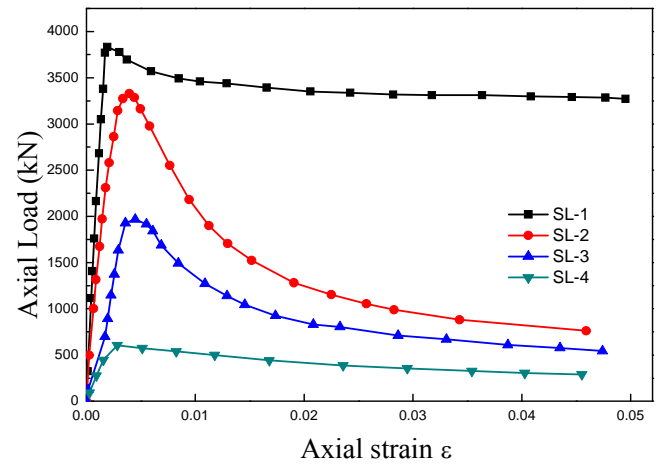

Figure 19. Effect of Slenderness Ratio

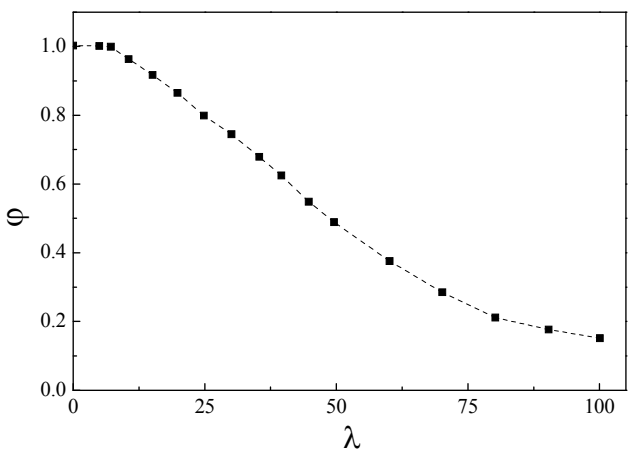

Figure 21. Typical $\varphi-\lambda$ relation of SRSCFSHS 


\section{A NEW APPROACH FOR PREDICTING STRENGTH OF SHORT SRSCFSHS COLUMN}

In this study, the approach of Eurocode 4 [17] (EC4) was adopted to estimate the compressive strength of the short SRSCFSHS columns (A $1 \mathrm{~b})$. According to the calculation approach in Eurocode 4, the compressive strength of short SRSCFSHS columns can be calculated by

$$
N_{\mathrm{w}}=A_{g} f_{Q}^{\prime}+A_{g} f_{y}^{t}+A_{g} f_{y}^{g}
$$

In the above equation, $f_{g}^{t}$ is the yield strength of steel tube, $f_{\varepsilon}^{\prime}$ is the cylinder compressive strength of concrete and $f_{y}$ is the yield strength of section steel. $A_{s}, A_{g}$ and $A_{g g}$ are the cross-sectional areas of the steel tube, core concrete and section steel, respectively.

Table 5 shows the comparison between the simulation results and the predicted results from Eq. 5 . It is found that the approach in Eurocode 4 underestimates the strength of SRSCFSHS specimens, and the maximum deviation reaches as great as $15 \%$. As can be seen in Table 3 , with the increase of steel tube ratio and steel tube strength, the maximum deviation reaches as great as $36 \%$, indicating that neglecting the confinement effect in SRSCFSHS column may lead to severe conservative predication for real design. Therefore, a reliable approach needs to be developed for predicting the load carrying capacity of SRSCFSHS columns.

The SRSCFSHS column can be regarded as a combination of CFST and section steel, in this way, the bearing capacity of SRSCFSHS can be expressed as follow:

$$
N_{\text {SRERST }}=N_{\text {GEST }}+N_{S Q}
$$

where $N_{\text {SEFYF }}$ is the load capacity of SRSCFSHS, $N_{\text {GEST }}$ is the load capacity of square CFST and $N_{S S}$ is load capacity of section steel.

Up to now, a number of models for predicting the load carrying capacity of CSFT tubular members have been proposed [27-29]. Tao [30] made comparison of these models, and found that the DBJ/T13-5 [26] gave comparatively accurate prediction. The equation in DBJ/T13-51 can be simplified as follow:

$$
\begin{aligned}
& f_{F Y}=\left(1.18+0.85 \xi f_{O K}\left(0.2 \alpha_{n} \xi_{1}<5\right)\right. \\
& N_{G F Y}=f_{F Y} A_{S S}
\end{aligned}
$$

where $\xi$ is a confinement factor, $f_{c k}$ is the characteristic compressive strength of concrete cube, $f_{s g y}$ is the strength index of CFST column and $A_{g e}$ is the cross-sectional areas of CFST column.

As for the strength of section steel $\left(N_{\mathscr{S}}\right)$, the local buckling of inner section steel $(\lambda \leqslant 15)$ can be avoided due to effective support of steel tube confined core concrete. Therefore section steel can fully contribute its strength to SRSCFSHS column. As has been analyzed above, the section steel reaches its peak strength after the yielding of SRSCFSHS column, indicating the strength of section steel has not been thoroughly utilized when the SRSCFSHS reached its peak strength. Therefore, $N_{M N^{\prime}}$ can be expressed as follow:

$$
N_{S S}=\lambda f_{u}^{s} A_{s s}
$$


where $f_{u}$ is the ultimate stress of steel, and $\mathbf{A}_{g z}$ is the cross-sectional area of section steel. In this equation, $\lambda$ is a coefficient considering the "hysteresis effect" of section steel, and $\lambda$ can be calculated as follow:

$\lambda=\frac{\nabla\left(g_{g}{ }^{2}\right.}{f(x)}$

where $\varepsilon_{e c}$ is the peak strain of the core concrete and can be calculated according to equation (3), which can also represent the peak strain of the SRSCFSHS column as can be seen in Figure (7). The $\sigma\left(a_{0}\right)$ represents the stress of the section steel when SRSCFSHS column reaches its peak load and $f_{\alpha}$ is the ultimate stress of the section steel.

Both $\sigma\left(\sigma_{\sigma o}\right)$ and $f_{u}^{g}$ can be calculated according to the equation (1), (2) and (3) above, therefore $\lambda$ can be expressed as following:

$A=\frac{2}{2}+\frac{E_{s} E_{\mathrm{N}}}{232 f_{\mathrm{f}}}$

As can be seen in equation (11), $\lambda$ will decrease with the increase of $f_{y}$, which indicates that there is no need to apply high strength section steel in SRSCFSHS column.

In this way, Eq. 6 can be modified as follow:

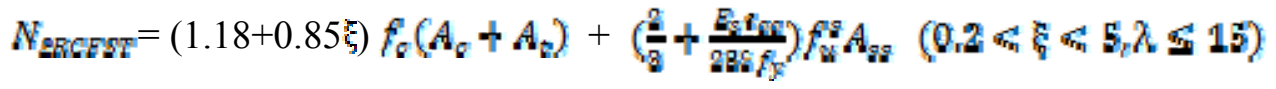

As can be seen in Table 4, the suggested equation appears to provide more reliable predictions with the maximum error less than $10 \%$. In order to verify the validity of the proposed equation, the comparison was also made between the experimental results and the predicted results from the proposed model. A total of seven specimens from the past experiments conducted by Wang [15] were adopted. Table 5 shows the comparison of the experimental results with the calculated results from the proposed equations. It is found that the proposed model can provide precise predications of the strength of tested SRSCFSHS columns.

Table 4. Comparison of the Simulation Results with the Modelling Results

\begin{tabular}{cccccc}
\hline Specimen & $N_{E \varepsilon}(k W)$ & $\begin{array}{c}N_{u}(k N) \\
{[\text { Eq. 5] }}\end{array}$ & $\begin{array}{c}N_{F F} / N_{w} \\
{[\text { Eq. 5] }}\end{array}$ & $\begin{array}{c}N_{w}(k N) \\
{[\text { Eq. 12] }}\end{array}$ & $\begin{array}{c}N_{F \xi} / N_{w} \\
{[\text { Eq. 12] }}\end{array}$ \\
\hline SS-1 & 3838 & 3308 & 1.16 & 3726 & 1.06 \\
SS-2 & 4408 & 3642 & 1.21 & 4544 & 1.05 \\
SS-3 & 4635 & 3768 & 1.23 & 4372 & 1.02 \\
SS-4 & 4753 & 3833 & 1.24 & 4442 & 1.07 \\
CS-1 & 4069 & 3477 & 1.17 & 4238 & 0.96 \\
CS-2 & 4181 & 3635 & 1.15 & 3700 & 1.03 \\
CS-3 & 4219 & 3835 & 1.1 & 3906 & 0.96 \\
CS-4 & 4330 & 4123 & 1.05 & 4123 & 0.94 \\
TS-1 & 4117 & 3402 & 1.21 & 4036 & 0.98 \\
TS-2 & 4648 & 3688 & 1.26 & 4694 & 1.07 \\
TS-3 & 4796 & 3633 & 1.32 & 4611 & 1.04 \\
TS-4 & 5033 & 3673 & 1.37 & 4748 & 1.05 \\
TR-1 & 3956 & 3269 & 1.21 & 3697 & 1.03 \\
TR-2 & 4717 & 3773 & 1.25 & 4579 & 1.06 \\
\hline
\end{tabular}




\begin{tabular}{llllll}
\hline TR-3 & 5515 & 4342 & 1.27 & 5202 & 1.08 \\
TR-4 & 6773 & 5131 & 1.32 & 6575 & 1.08 \\
TR-5 & 7596 & 5585 & 1.36 & 7447 & 0.95 \\
SR-1 & 3738 & 3307 & 1.13 & 3560 & 1.09 \\
SR-2 & 4021 & 3466 & 1.16 & 3757 & 1.04 \\
SR-3 & 4344 & 3590 & 1.21 & 4137 & 1.06 \\
SR-4 & 4735 & 3849 & 1.23 & 5037 & 0.97 \\
SR-5 & 5282 & 4192 & 1.26 & 5128 & 1.06 \\
\hline
\end{tabular}

Table 5. Comparison of the Experimental Results with the Modelling Results

\begin{tabular}{cccccc}
\hline Specimen & $N_{E W}(k N)$ & $\begin{array}{c}N_{u}(k N) \\
{[\text { Eq. 5] }}\end{array}$ & $\begin{array}{c}N_{E N} / N_{\text {u }} \\
\text { [Eq. 5] }\end{array}$ & $\begin{array}{c}N_{w}(k N) \\
{[\text { Eq. 12] }}\end{array}$ & $\begin{array}{c}N_{E W} / N_{\text {u }} \\
\text { [Eq. 12] }\end{array}$ \\
\hline S5L10 & 4047 & 3669 & 1.1 & 3929 & 1.05 \\
S5H10 & 4882 & 4363 & 1.12 & 5085 & 0.98 \\
S4L10 & 3980 & 3495 & 1.14 & 3790 & 1.04 \\
S4H10 & 4820 & 4206 & 1.15 & 4918 & 0.96 \\
\hline
\end{tabular}

\section{CONCLUSIONS}

In this paper, the mechanical behaviors of SRSCFSHS columns in uniaxial compression were investigated with nonlinear finite element analysis. The validity of the applied finite element models was verified with existing experimental results. The composite effect of SRSCFSHS column was comprehensively studied with the finite element model. The strength and ductility of SRSCFSHS are much higher than that of the square CFST column with same cross section due to the existence of inner section steel. The inner section steel can provide "strength reserve" for the SRSCFSHS columns. On the other hand, the local buckling of inner section steel can be avoided due to effective support of square steel tube confined concrete.

A total of twenty-six SRSCFSHS columns were modelled to investigate the effects of different parameters on the mechanical behaviors, including the steel tube ratio $\left(\alpha_{t}\right)$, section steel ratio $\left(\alpha_{g}\right)$, concrete strengths $\left(f_{c}\right)$, yield strength of steel tube $\left(f_{y}^{*}\right)$, yield strength of section steel $\left(f_{y}^{*}\right)$ and the slenderness ratio $(\lambda)$. According to the calculation results, the peak strength and initial stiffness of CFST columns increases with the increase of the mentioned parameters except for slenderness ratio. However, the increase of section steel ratio $\left(\alpha_{g}\right)$, yield strength of steel tube $\left(f_{y}\right)$ or section steel $\left(f_{y}^{z}\right)$ has little influence on the axial compression behaviors of SRSCFSHS columns after peak strength. The SRSCFSHS columns generally shift from strength softening behavior to strength hardening behavior with increasing steel tube ratio $\left(\alpha_{t}\right)$. The increase of slenderness ratio $(\lambda)$ will change the failure model of the SRSCFSHS column. When $\lambda$ is smaller than 15 , the SRSCFSHS column can be classified as a short column.

The model in Eurocode 4 comparatively underestimates the load carrying capacity of of SRSCFSHS column due to neglecting the strength increase of core concrete and section steel caused by confinement effect. In this study, a new model for predicting the strength of SRSCFSHS columns was proposed and verified with the experimental results.

\section{ACKNOWLEDGMENT}

Financial support of this work by National Natural Science Foundation of China under 51278118 and Priority Academic Program Development of Jiangsu High Education Institutions under 1105007002 is gratefully acknowledged. 


\section{REFERENCE}

[1] Bungale, S.T., "Structural Analysis and Design of Tall Buildings: Steel and Composite Construction", The Chemical Rubber Company Press, 2011.

[2] Liu, S.W., Liu, Y.P. and Chan, S.L., "Advanced Analysis of Hybrid Steel and Concrete Frames: Part 1: Cross-section Analysis Technique and Second-order Analysis", Journal of Constructional Steel Research, 2012, Vol. 70, pp. 326-336.

[3] Liu, S.W., Liu, Y.P. and Chan, S.L., "Advanced Analysis of Hybrid Steel and Concrete Frames: Part 2: Refined Plastic Hinge and Advanced Analysis", Journal of Constructional Steel Research, 2012, Vol. 70, pp. 337-349.

[4] Han, L.H., Li, W. and Bjorhovde, R., "Developments and Advanced Applications of Concrete-Filled Steel Tubular (CFST) Structures: Members", Journal of Construction Steel Research, 2014, Vol.100, No.5, pp. 211-228.

[5] Kodur, V.K., "Performance-based Fire Resistance Design of Concrete-filled Steel Columns", Journal of Construction Steel Research, 1999, Vol.51, No.1, pp. 21-36.

[6] Varmaa, A.H., James, M. and Riclesb, R.S., "Seismic Behavior and Modeling of High-strength Composite Concrete-filled Steel Tube (CFT) Beam-columns", Journal of Construction Steel Research, 2002, Vol.58, No.5, pp. 725-758.

[7] Fu, Z.H., Ji, B.H. and Lv, L., "Behavior of Lightweight Aggregate Concrete Filled Steel Tubular Slender Columns under Axial Compression”, Advanced Steel Construction, 2011, Vol.7, No.2, pp. 144-156.

[8] Cai, J., Pan, J. and Shan, Q., "Failure Mechanism of Full-size Concrete Filled Steel Circle and Square Tubes under Uniaxial Compression", Science China Technological Sciences, 2015, Vol. 58, No. 10, pp. 1638-1647.

[9] Wang, Y.Y., Wu, X.R. and Gang, Y., "Application of Concrete Filled Steel Tubular Arch Bridges in China", Taylor Francis Group, 2012, pp. 465-472.

[10] Pisano, A.A., Fuschi, P. and Domenico, D., "Peak Loads and Failure Modes of Steel-reinforced Concrete Beams: Predictions by Limit Analysis", Engineering Structures, 2013, Vol. 56, No. 5, pp. 477-488.

[11] Ehab, E., Young, B. and Dennis, L., "Eccentrically Loaded Concrete Encased Steel Compodite Columns", Thin-Walled Structure, 2011, Vol.49, No.1, pp.53-65.

[12] Sherif, E.T. and Gregory, G.D., "Strength and Ductility of Concrete Encased Composite Columns", Journal of Structural Engineering, ASCE, 1999, Vol.125, No.9, pp.1009-1019.

[13] Chen, C.H., Wang, C.K. and Sun, H.Z., "Experimental Study on Seismic Behavior of Full Encased Steel-Concrete Composite Columns", Journal of Structural Engineering, ASCE, 2014, Vol.140, No.6, pp. 1-10.

[14] Zhu, M., Liu, J. and Wang, Q., "Experimental Research on Square Steel Tubular Columns Filled with Steel-reinforced Self-consolidating High-strength Concrete under Axial Load" Engineering Structures, 2010, Vol.32, No.8, pp. 2278-2286.

[15] Wang, L.G., Zhao, T.F. and Li, H.N., "Experimental Research and Theoretical Analysis of Square Steel Tube Columns Filled with Steel-reinforced High-strength Concrete Subjected to Eccentric Loading"(in Chinese), Journal of Building Structure, 2010, Vol.31, No.7, pp. 907-915.

[16] Zhao, T.F. and Wang, L.G., "Calculation on Compression-bending of Square Tube Filled with Steel Reinforced High Strength Concrete" (in Chinese), Engineering Mechanics, 2008, Vol. 25, No.10, pp. 122-125.

[17] Eurocode 4, "Design of Composite Steel and Concrete Structures-part1-1: General Rules-structural Rules for Buildings", Brussels: European Committee for Standardization, 2004. 
[18] Li, G.C., Di, C.Y. and Tian, L., "Nonlinear Finite Element Analysis On Long Columns Of High-Strength Concrete-Filled Square Steel Tube With Inner CFRP Circular Tube Under Axial Load", Advanced Steel Construction, 2013, Vol.9, No.2, pp. 124-138.

[19] Hatami, S., Rahmani, A. and Parvaneh, A., "A Parametric Study on Seismic Characteristics of Cold-formed Steel Shear Walls by Finite Element Modeling", Advanced Steel Construction, 2014, Vol.10, No.1, pp. 53-71.

[20] Hibbitt, K., “ABAQUS Version 6. 7: Theory Manual, Users' Manual, Verification Manual and Example Problems Manual", 2007.

[21] Han, L.H., Yao, G. H. and Tao, Z., "Performance of Concrete-filled Thin-walled Steel Tubes under Pure Torsion", Thin-Walled Structure, 2007, Vol.45, No.1, pp.24-36.

[22] Tao, Z., Wang, Z. B. and Yu, Q., "Finite Element Modelling of Concrete-filled Steel Stub Columns under Axial Compression", Journal of Construction Steel Research, 2013, Vol.89, No. 2013, pp.121-131.

[23] ACI318-11, "Building Code Requirements for Structural Concrete and Commentary", Detroit (USA): American Concrete Institute, 2011.

[24] Hillerborg, A., Modéer, M. and Petersson, P.E., "Analysis of Crack Formation and Crack Growth in Concrete by Means of Fracture Mechanics and Finite Elements", Cement and Concrete Research, 1976, Vol.6, No.6, pp. 773-782.

[25] Park, R., "Evaluation of Ductility of Structures and Structural Assemblages from Laboratory Testing", Bulletin of the New Zealand National Society for Earthquake Engineering, 1989, Vol.22, No.3, pp. 155-166.

[26] An, Y. F., Han, L. H. and Zhao, X. L., "Behavior and Design Calculations on Very Slender Thin-walled CFST Columns”, Thin-Walled Structure, 2012, Vol.53, No.1, pp. 161-175.

[27] AIJ, "Recommendations for Design and Construction of Concrete Filled Steel Tubular Structures", Tokyo, Japan: Architectural Institute of Japan (AIJ), 2008.

[28] ANSI/AISC 360-10, "Specification for Structural Steel Buildings", Chicago, USA: American Institute of Steel Construction (AISC), 2010.

[29] DBJ/T13-51-2010, "Technical Specifications for Concrete-Filled Steel Tubular Structures" (in Chinese), The Housing and Urban-Rural Development Department of Fujian Province, 2010 .

[30] Tao. Z. and Han. L.H., "Design of Concrete Filled Square Steel Tubular Members" (in Chinese), Journal of Harbin University of Engineering \&Architecture, 2001, Vol.34, No.3, pp. 16-19. 